\title{
Small Molecule Inhibitors of Human DNA Polymerase $\lambda$
}

\author{
Tobias Strittmatter, Bettina Bareth, Timo A. Immel, Thomas Huhn, Thomas U. Mayer, and Andreas Marx* \\ Departments of Chemistry and Biology, Konstanz Research School Chemical Biology, University of Konstanz, Universitätsstr. 10, \\ 78457 Konstanz, Germany
}

Supporting Information

ABSTRACT: To discover chemical probes to further under stand the function of individual DNA polymerases, we estab lished a generally applicable high throughput screening. By applying this technique we discovered three novel inhibitor classes of human DNA polymerase $\lambda$ (DNA Pol $\lambda$ ), a key enzyme to maintain the genetic integrity of the genome. The rhodanines, classified as an excellent drug scaffold, were found to be the most potent inhibitors for DNA Pol $\lambda$. Importantly, they are up to 10 times less active against the highly similar DNA polymerase $\beta$. We investigated basic structure activity relationships. Furthermore, the rhodanines showed pharmacological activity in two human cancer cell lines. So the here reported small molecules could serve as useful DNA Pol $\lambda$ probes and might serve as starting point to develop novel therapeutic agents.

\begin{abstract}
$\mathrm{C}^{\text {ach }}$ organism is affected by DNA damaging agents. To Emaintain the genetic integrity of its genome, sophisticated repair systems have evolved. Errors in this process can lead to severe developmental defects and cancer. Key enzymes for the maintenance of the integrity of the genome are DNA poly merases involved in the DNA synthesis, repair of DNA lesions, and recombination. ${ }^{14}$ In humans 15 DNA polymerases are known. ${ }^{4}$ The entire process of DNA replication takes minutes, and individual steps take place in split seconds. ${ }^{5}$ Given their fast mode of action, cell permeable small molecules are ideally suited to interfere in this highly dynamic process. However, to under stand in depth the function of individual DNA polymerases, appropriate small molecule inhibitors are required. These mole cules might not only be of great value for basic research but may also open up novel avenues for the treatment of diseases related to genome integrity. ${ }^{6}{ }^{8}$ In this work, we focused on the recently described human DNA polymerase $\lambda$ (DNA Pol $\lambda$ ), a member of the DNA polymerase $\mathrm{X}$ family. ${ }^{9}$ The exonuclease deficient DNA $\operatorname{Pol} \lambda$ contains all the critical residues involved in DNA binding, nucleotide binding and selection, and catalysis of DNA poly merization that are conserved in DNA polymerase $\beta$ (DNA Pol $\beta$ ). Thus, the sequence and the three dimensional structure of the catalytic core in the $\mathrm{C}$ terminal part of DNA Pol $\lambda$ (residues 244-575) are highly similar to DNA Pol $\beta$ (Figure 1A, B)., ${ }^{9,10}$ DNA Pol $\lambda$ can synthesize DNA in a template dependent manner, de novo, and possesses terminal deoxynucleotidyl trans ferase (TDT) activity. ${ }^{11}$ 15 It is implicated that DNA Pol $\lambda$ is involved in gap filling during nonhomologous end joining, ${ }^{16,17}$ translesion synthesis, ${ }^{18,19}$ and base excision repair (BER). ${ }^{20,21}$ Moreover, studies with chicken DT40 cells, ${ }^{22}$ as well as mammalian fibroblasts, showed that DNA Pol $\lambda$ has a backup role for DNA Pol $\beta$ in BER. ${ }^{23}$ Reportedly, high levels of DNA polymerases of the $\mathrm{X}$ family might cause genomic instability. ${ }^{4}$
\end{abstract}

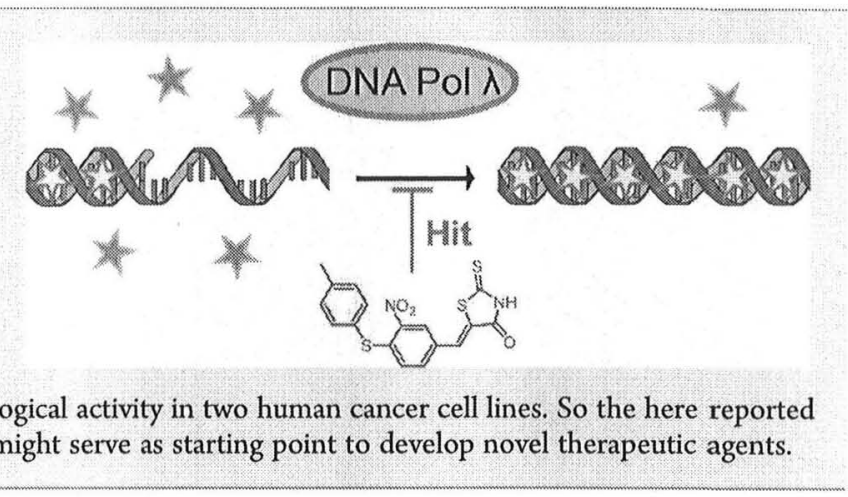

A recent investigation of the expression patterns of specialized DNA polymerases in 68 different tumor samples revealed that in more than $45 \%$ of these tumors at least one specialized DNA polymerase was 2 fold enhanced expressed. Of particular interest was the fact that over $30 \%$ of all samples had either DNA Pol $\lambda$ or $\beta$ overexpressed. ${ }^{24}$ Consequently, both DNA polymerases are discussed as promising new drug targets for the treatment of cancer. ${ }^{2}{ }^{4,25}$ One goal for targeting these DNA polymerases is the inhibition of the repair of DNA adducts caused by DNA damaging anticancer agents. To the best of our knowledge, known inhibitors of the polymerase function of DNA Pol $\lambda$ are exclusively based on natural products, ${ }^{3}$ and the strongest known inhibitor is $(-)$ epigallocatechin gallate (EGCG) isolated from green tea reported with a half maximal inhibitory concentration $\left(\mathrm{IC}_{50}\right)$ value of $3.8 \mu \mathrm{M}^{26}$

To identify inhibitors of DNA polymerases, we adapted our recently described SYBR Green based assay ${ }^{27,28}$ for inhibitor high throughput screening (HTS) (Figure 1C). The increase of the fluorescence signal caused by SYBR Green I emitting upon binding to double stranded (ds) DNA was used as readout for the activity of DNA Pol $\lambda$. For the parallelized primer extension reactions (PEX) a 20 nucleotide primer strand was annealed to a 90 nucleotide template strand. Primer extension results in high concentrations of double stranded DNA when DNA Pol $\lambda$ was not inhibited. On the contrary, when DNA Pol $\lambda$ was inhibited, the primer was not extended and the fluorescence was low in relation to the control (Supporting Information). A 9009 member pharmacophore library (purchased from Maybridge) was screened in duplicate at a concentration of about $65 \mu \mathrm{M}$.

Received: November 19, 2010

Accepted: December 31, 2010

Published: December 31, 2010 


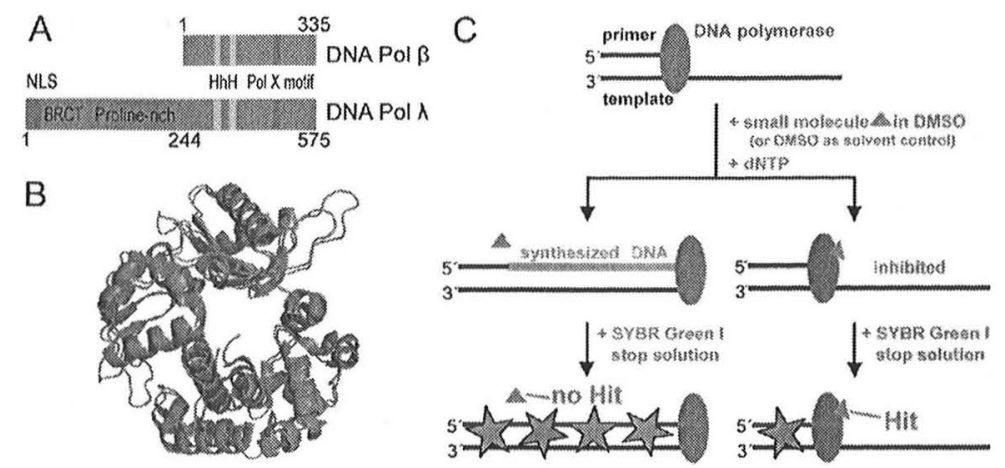

Figure 1. (A) Schematic diagram of DNA Pol $\beta$ (red) and DNA Pol $\lambda$ (green). DNA Pol $\lambda$ consists of a nuclear localization signal (NLS), a BRCA1 C terminal (BRCT) domain (residues 36 132), a proline rich region (residues 133 243), and a DNA Pol $\beta$ like catalytic core region (residues 244 575), with a helix hairpin helix $(\mathrm{HhH})$ and a DNA polymerase X motif. ${ }^{9}$ (B) Superimposition of the DNA Pol $\beta$ like catalytic core region (residues 244 575) of DNA Pol $\lambda$ (green) and DNA Pol $\beta$ (red). PDB IDs 2PFN and 2FMP (shown without DNA). (C) SYBR Green based HTS assay. DNA polymerase incorporates dNTP, thereby synthesizing ds DNA. After treating with SYBR Green I, high concentrations of ds DNA cause an increased fluorescence signal (on the left, no hit or control). With inhibited DNA Pol $\lambda$, the primer was not extended and the fluorescence was low in relation to the control (on the right, hit).

Compounds were considered as "hits" if the relative fluorescence was significantly lower than the positive control (Supporting Information). It should be mentioned that the identified collec tion of hits might not be complete since additional active compounds might have been missed during screening. The identified 159 hits were additionally studied with a more sensi tive method. Therefore, PEX with a shorter 33 nucleotide tem plate and radioactive labeled primer with the same sequence context were used. In this way we could identify 11 highly ac tive compounds out of the 159 hits. On the basis of the structures, the 11 hits can be subdivided in three inhibitor classes: Class I are rhodanines ( 5 arylidene 2,4 thiazolidinediones), class II has members of carbohydrazides, and class III contains a common 2,4 pentadione substructure element (Figure 2A; Supplementary Table S1).

Next, the three classes were analyzed toward inhibiting the DNA polymerase function of DNA Pol $\beta$. The rhodanines, classified as an excellent scaffold for the development of biolo gically active molecules, ${ }^{29}{ }^{31}$ inhibited the polymerase function of DNA Pol $\lambda$ and were able to discriminate between DNA $\operatorname{Pol} \lambda$ and $\beta$. Compound $\mathbf{1}$ is the most potent discriminating inhibitor. To confirm the chemical identity, 1 was resynthesized (Supporting Information). The resynthesized 1 was equally potent and selective. To determine the exact $\mathrm{IC}_{50}$ values of the compounds against DNA Pol $\lambda$ and $\beta$, we used a radioactive PEX assay in the presence of increasing concentrations of inhibitor or DMSO as a solvent control (Supporting Information). We found that 1 inhibits dose dependently the polymerization function of DNA Pol $\lambda$ with an $\mathrm{IC}_{50}$ value of $5.9 \mu \mathrm{M}$ and DNA Pol $\beta$ with an $\mathrm{IC}_{50}$ of $64.4 \mu \mathrm{M}$ and could hence discriminate between the two highly similar family $X$ DNA polymerases with a factor of $\sim 10$ (Figure 2B,C). To further evaluate compound 1, we used EGCG in a side by side comparison using the radioactive PEX assay. We found that EGCG is less active as $\mathbf{1}$ in this assay (Figure 2D, Supplementary Figure S2), and thus 1 was selected as lead for further investigations.

To investigate if 1 competes with the natural dNTP substrates, we conducted a PEX assay in the presence of a given amount of inhibitor and increasing concentrations of dNTPs (Figure 2E). The absence of reaction products even in the presence of increasing amounts of dNTP indicates that $\mathbf{1}$ inhibits DNA Pol $\lambda$ without directly competing for the same binding site.
It was reported that human DNA Pol $\lambda$ has a TDT activity, and its involvement in recombination events was suggested. ${ }^{32,33}$ Thus, to test the inhibitory potential of $\mathbf{1}$, we investigated TDT activity using a radioactive assay of single stranded primer extension (Figure 2F,G) similar to what has been described before. ${ }^{34} \mathrm{We}$ found that 1 inhibits dose dependently the TDT function of DNA Pol $\lambda$ with an $\mathrm{IC}_{50}$ value of $4.5 \mu \mathrm{M}$.

To establish basic structure - activity relationships (SAR), we subdivided 1 in a molecular scaffold. The scaffold consists of three variable parts, $\mathrm{R}^{1}, \mathrm{R}^{2}$, and $\mathrm{R}^{3}$, which are connected via a phenyl ring and a variable linkage $Z$, respectively (Table 1 ). Next, we tested scaffold oriented small molecules 12-35 (Table 1, Supporting Information) at $20 \mu \mathrm{M}$ concentration in the radio active DNA Pol $\lambda$ PEX assay (Table 1, Supplementary Figure S3). To identify the core inhibitory structure, the compounds 12-16 were made accessible. These compounds are less active. By comparing the analogues $1,3,4$, and $17-21$, we noticed that molecules tend to higher activity with the linkage $\mathrm{Z}$ in the position para to the rhodanine moiety $A$. However, compounds 4 and 21 with 4 chlorophenyl substituents in $\mathrm{R}^{3}$ do not follow this trend. The 4 methylphenyl substituent $\left(R^{3}\right)$ in 1 also seems to have influence on the activity, because by its substitution with 4 chlorophenyl (21) or 4 bromophenyl (22), the analogues lost activity. The same effect was observed for 18 and 23 , because the substitution of the trifluoromethyl group in $\mathrm{R}^{3}$ (18) by a hydrogen atom (23) resulted in a much less active compound. Comparing compounds 24,25 , and 26 , it is evident that the variation of the substituents in $R^{2}$ is also able to influence the activity. In contrast, the thioether as linkage $\mathrm{Z}$ proved not to be essential for high activities and could be replaced by ester $(27,28$, $29)$, phenyl benzyl ether $(24,25,26,30)$, or diphenyl ether (31) without affecting activity. The importance of the heterocyclic rhodanine moiety A was confirmed by several experiments. The substitution of moiety $A$ with the 2,4 thiazolidinedione moiety B was confirmed by the analysis of compound $24,27,28$ and 32. The compounds 27 and 32 with the 2,4 thiazolidinedione moiety $B$ in position $R^{1}$ are active but less active than molecules with the moiety $A(24,28)$. In addition 33 , with two nitro substituents in positions $\mathrm{R}^{1}$ and $\mathrm{R}^{2}$, was tested in comparison to 4 and 21 . In 4 and 21 each one nitro substituent is replaced by moiety $\mathrm{A}$, compared with 33 . Compound 33 is unable to 
A
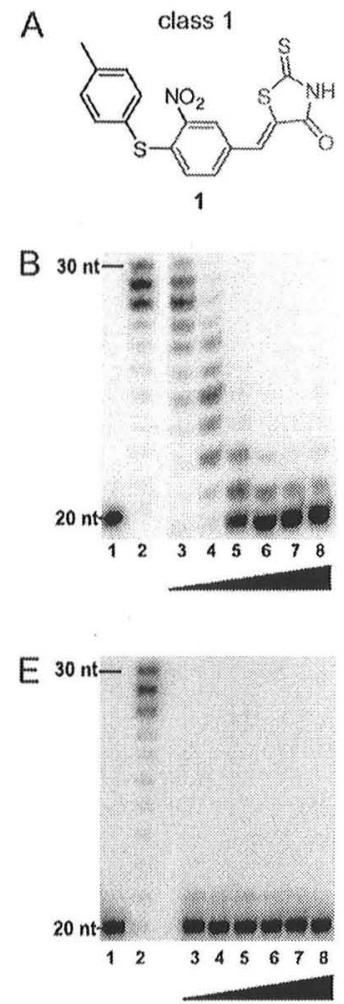<smiles>O=C(NCc1cccc(Cl)c1)NN=Cc1cc(Cl)ccc1O</smiles>

5

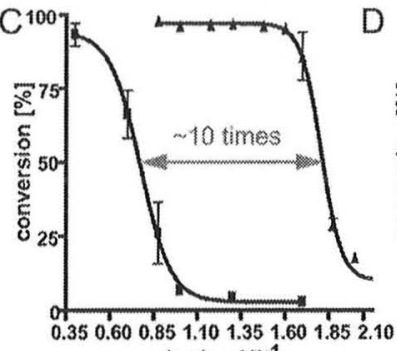

$\log (c \mu M)^{-1}$

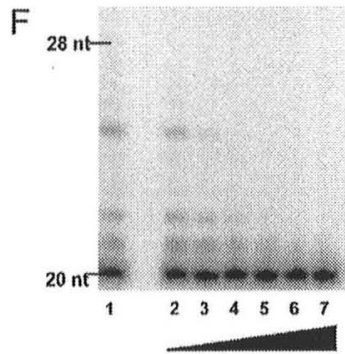

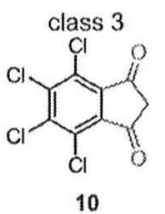

10
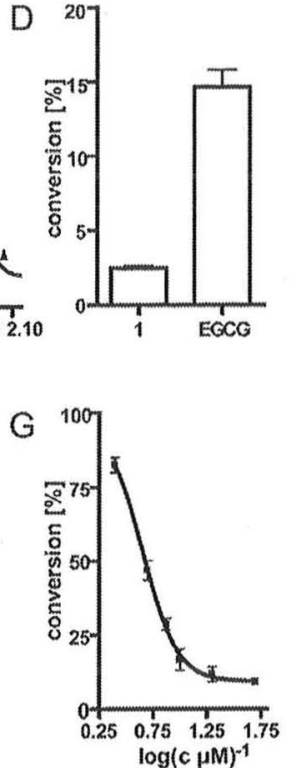

Figure 2. (A) Chemical structures of the most potent hit of each DNA Pol $\lambda$ inhibitor class. According the blue substructures, the classes were divided (Supplementary Table S1). Compound 1 was the most potent DNA Pol $\lambda$ inhibitor and discriminates between DNA Pol $\lambda$ and $\beta$. (B) Representative PAGE analysis of $\mathrm{IC}_{50}$ determination of DNA Pol $\lambda$ for 1. Lane 1: Primer only; lane 2: DMSO control; lane 38 : same as lane 2 increasing concentrations of $1(2.5,5.0,7.5,10.0,20.0,50.0 \mu \mathrm{M}$ compound). (C) Dose response curves of resynthesized compound 1 , which inhibited dose dependently the polymerization function of DNA Pol $\lambda(\mathbf{G})$ with an $\mathrm{IC}_{50}$ value of $5.9 \pm 1.1 \mu \mathrm{M}$ and DNA Pol $\beta(\Delta)$ with an IC $\mathrm{I}_{50}$ of $64.4 \pm 1.0 \mu \mathrm{M}$. Averages of three independent experiments and standard deviations are shown. (D) Potency of compound 1 compared with EGCG using the same reaction conditions (100 $\mu \mathrm{M}$ compound). Averages of three independent experiments and standard deviations are shown. (E) PAGE analysis of the DNA Pol $\lambda$ PEX assay with varied dNTP concentrations. Lane 1: Primer only; lane 2: DMSO control (get to $100 \%$ conversion); lanes 3 8: 50 $\mu$ M 1 and increasing concentrations of dNTPs $(15,30,60,120,240,480 \mu \mathrm{M})$. (F) PAGE analysis showing the influence of 1 on TDT function of DNA Pol $\lambda$. Lane 1: DMSO control; lane 27 : increasing concentrations of 1 in DMSO (2.5, 5.0, 7.5, 10.0, 20.0, 50.0 $\mu$ M compound). (G) Dose response curve. The conversion of primer depicted in Figure 2F, lane 1 was set as $100 \%$. Compound 1 inhibited dose dependently the TDT function of DNA Pol $\lambda$ ( $\square$ ) with an $\mathrm{IC}_{50}$ value of $4.5 \pm 1.1 \mu \mathrm{M}$. In general the averages of three independent experiments and standard deviations are shown. For details see also the Supporting Information.

inhibit the DNA Pol $\lambda$ at $20 \mu \mathrm{M}$, but the substitution of a nitro substituent by the moiety $A$ formed a highly active inhibitor. Consistently, inhibitory activity required the con densation of benzaldehyde 34 with rhodanine. The substitu tion of moiety $\mathrm{A}$ in 1 with the $N$ allylrhodanine moiety $\mathrm{C}$ was investigated by the synthesis of 35 . Compound 35 is unable to inhibit DNA Pol $\lambda$, and for this reason it is conceivable that the heterocyclic moiety in $\mathbf{1}$ and its active analogues interact with DNA Pol $\lambda$ via hydrogen bonds. Perhaps these proteinligand interactions are prevented by moiety $\mathrm{C}$ in 35 . All of these data indicate that the rhodanine moiety $\mathrm{A}$ is very important for a highly active inhibitor. Next, we tested small molecules that had an inhibitory activity against DNA Pol $\lambda$ in the PEX assay of at least $90 \%$ for their effect on DNA Pol $\beta$. For these DNA Pol $\beta$ PEX assays compounds were used at $50 \mu \mathrm{M}$. (Table 1, Supplementary Figure S4). Interestingly, by modifying position $\mathrm{R}^{2}$ and $\mathrm{R}^{3}$ of the scaffold, we generated the active but unselective compounds 19,20 , and 28 . These findings suggest that the rodanines act in the $\mathrm{C}$ terminal part of DNA Pol $\lambda$, as this part is highly conserved in both DNA polymerases (Figure 1A, B). Compounds 18, 24, 29, and 31 are still able to discriminate between the two DNA polymerases, and thus the $\mathrm{IC}_{50}$ values for DNA Pol $\lambda$ and $\beta$ were also investigated (Table 1, Supporting Information).

In general, rhodanines are classified as nonmutagenic, ${ }^{35}$ and a long term study on the clinical effects of the rhodanine based Epalrestat demonstrated that it is well tolerated by patients. ${ }^{36}$ Given that DNA Pol $\lambda$ is discussed as a promising cellular target, especially in the case of cancer treatment, ${ }^{2}{ }^{4}$ we determined the half maximal inhibitory concentration of the cell viability $\left(\mathrm{EC}_{50}\right)$ of the discovered rhodanines $1,18,24,29$, and 31 using two human cancer cell lines, a cervix carcinoma cell line, HeLa S3, and a hepatocellular carcinoma cell line, Hep G2 (Figure 3). In both of these cancer types DNA Pol $\lambda$ is overexpressed. ${ }^{24,37}$ As shown in Supplementary Figure S7, viability of both cancer cell lines was suppressed dose dependently by each inhibitor after $48 \mathrm{~h}$ incubation. Compound 18 with $\mathrm{EC}_{50}$ values of 7.9 and $6.1 \mu \mathrm{M}$ against HeLa and Hep cells, respectively, was most toxic. The 
Table 1. SAR of 1 and Its Analogues in DNA Pol $\lambda$ and DNA Pol $\beta$ PEX Assays ${ }^{a}$

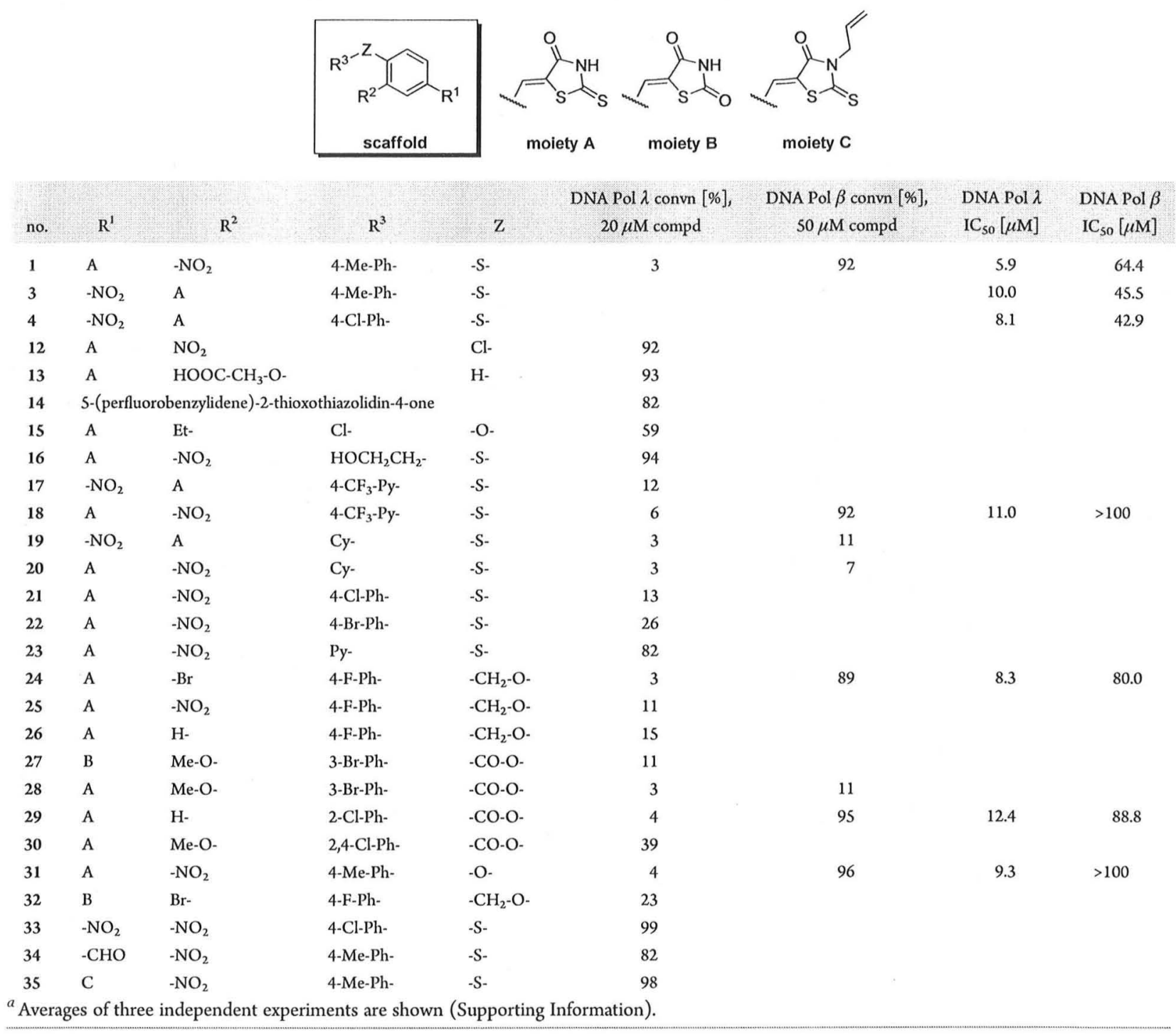

other compounds affected the viability of these cell lines at concentrations 2 to 5 fold higher than the $\mathrm{IC}_{50}$ values of DNA $\operatorname{Pol} \lambda$ (Table 1). These results suggest that $1,24,29$, and 31 are appropriate small molecule probes.

In conclusion, we established a new generally applicable HTS for small molecule inhibitors of DNA polymerases. With the aid of this method and a radioactive PEX assay, we discovered three novel inhibitor classes of the DNA poly merase function of the human DNA Pol $\lambda$ : the rhodanines, the carbohydrazides, and compounds with a common 2,4 pentadione substructure. The rhodanines were the most potent inhibitors and were able to discriminate with a factor 5 to 10 between the DNA Pol $\lambda$ and $\beta$. The structure of the most potent molecule $1\left(\mathrm{IC}_{50}=5.9 \mu \mathrm{M}\right)$ was confirmed via resynthesis. We investigated some basic SAR and thereby we discovered other inhibitors whose properties are comparable with 1 . We compared these compounds with the most active known inhibitor EGCG and found that the herein reported rhodanines are currently the strongest inhibitors for DNA

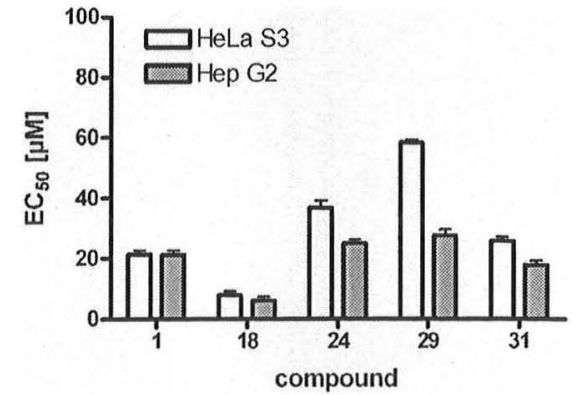

Figure 3. Results of cell viability measurements. Increasing concentra tions of compounds $1,18,24,29$, and 31 were used to estimate the $\mathrm{EC}_{50}$. Averages of four independent experiments and standard deviations are shown (Supporting Information and Supplementary Figure S7).

Pol $\lambda$. In addition the rhodanines showed pharmacological activity in cervix carcinoma and hepatocellular carcinoma cell 
lines, and for this reason the discovered small molecules could serve as useful chemical DNA Pol $\lambda$ probes and as a starting point to develop novel therapeutic agents.

\section{METHODS}

The Supporting Information contains full experimental details for the screening of the compound library, the synthesis, and the assays for biological in vitro and in vivo evaluation of the compounds.

\section{ASSOCIATED CONTENT}

Supporting Information. This material is available free of charge via the Internet at http:// pubs.acs.org.

\section{AUTHOR INFORMATION}

\section{Corresponding Author}

*andreas.marx@uni konstanz.de, thomas.u.mayer@uni konstanz.de.

\section{ACKNOWLEDGMENT}

We gratefully acknowledge funding and scientific support by the Konstanz Research School Chemical Biology. We also thank N. Hardt, M. Drum, and B. Holzberger for helpful discussions, $M$. Bein for help with the AlamarBlue assay, and $\mathrm{K}$. Bergen for the help with Figure 1B.

\section{REFERENCES}

(1) McCulloch, S. D., and Kunkel, T. A. (2008) The fidelity of DNA synthesis by eukaryotic replicative and translesion synthesis poly merases. Cell Res. 18, 148161.

(2) Loeb, L. A., and Monnat, R. J., Jr. (2008) DNA polymerases and human disease. Nat. Rev. Genet. 9, 594604.

(3) Maga, G., and Hübscher, U. (2008) Repair and translesion DNA polymerases as anticancer drug targets. Anti Cancer Agents Med. Chem. 8, 431447.

(4) Hübscher, U., Spadari, S., Villani, G., Maga, G. (2010) DNA Polymerases: Discovery, Characterization and Functions in Cellular DNA Transactions, World Scientific, Singapore.

(5) Johnson, K. A. (2004) DNA Polymerases: Kinetics and Mecha nism, in Encyclopedia of Biological Chemistry (William, J. L., Lane, M. D., Eds.), pp 734 739, Elsevier, New York.

(6) Mayer, T. U. (2003) Chemical genetics: tailoring tools for cell biology. Trends Cell Biol. 13, 270277.

(7) Walsh, D. P., and Chang, Y. T. (2006) Chemical genetics. Chem. Rev. 106, 24762530.

(8) Florian, S., Hümmer, S., Catarinella, M., and Mayer, T. U. (2007) Chemical genetics: reshaping biology through chemistry. HFSP J. 1 , 104114.

(9) Garcia Diaz, M., Dominguez, O., Lopez Fernandez, L. A. de Lera, L. T., Saniger, M. L., Ruiz, J. F., Parraga, M., Garcia Ortiz, M. J., Kirchhoff, T., del Mazo, J., Bernad, A., and Blanco, L. (2000) DNA polymerase $\lambda(\mathrm{Pol} \lambda)$, a novel eukaryotic DNA polymerase with a potential role in meiosis. J. Mol. Biol. 301, 851867.

(10) Garcia Diaz, M., Bebenek, K., Krahn, J. M., Kunkel, T. A., and Pedersen, L. C. (2005) A closed conformation for the Pol $\lambda$ catalytic cycle. Nat. Struct. Mol. Biol. 12,9798.

(11) Garcia Diaz, M., Bebenek, K., Sabariegos, R., Dominguez, O. Rodriguez, J., Kirchhoff, T., Garcia Palomero, E., Picher, A. J., Juarez, R. Ruiz, J. F., Kunkel, T. A., and Blanco, L. (2002) DNA polymerase $\lambda$, a novel DNA repair enzyme in human cells. J. Biol. Chem. 277, 1318413191.

(12) Shimazaki, N., Yoshida, K., Kobayashi, T., Toji, S., Tamai, K., and Koiwai, O. (2002) Over expression of human DNA polymerase $\lambda$ in E. coli and characterization of the recombinant enzyme. Genes Cells 7, 639651 .
(13) Ramadan, K., Shevelev, I. V., Maga, G., and Hübscher, U. (2002) DNA polymerase $\lambda$ from calf thymus preferentially replicates damaged DNA. J. Biol. Chem. 277, 1845418458.

(14) Ramadan, K., Maga, G., Shevelev, I. V., Villani, G., Blanco, L. and Hübscher, $U$. (2003) Human DNA polymerase $\lambda$ possesses terminal deoxyribonucleotidyl transferase activity and can elongate RNA primers: implications for novel functions. J. Mol. Biol. 328, 6372

(15) Ramadan, K., Shevelev, I., and Hübscher, U. (2004) The DNA polymerase X family: controllers of DNA quality?. Nat. Rev. Mol. Cell Biol. 5, 10381043.

(16) Lee, J. W., Blanco, L., Zhou, T., Garcia Diaz, M., Bebenek, K. Kunkel, T. A., Wang, Z., and Povirk, L. F. (2004) Implication of DNA polymerase $\lambda$ in alignment based gap filling for nonhomologous DNA end joining in human nuclear extracts. J. Biol. Chem. 279, 805811.

(17) Nick McElhinny, S. A., Havener, J. M., Garcia Diaz, M., Juarez, R., Bebenek, K., Kee, B. L., Blanco, L., Kunkel, T. A., and Ramsden, D. A (2005) A gradient of template dependence defines distinct biological roles for family X polymerases in nonhomologous end joining. Mol. Cell 19,357366 .

(18) Maga, G., Villani, G., Crespan, E., Wimmer, U., Ferrari, E., Bertocci, B., and Hübscher, U. (2007) 8 Oxo guanine bypass by human DNA polymerases in the presence of auxiliary proteins. Nature 447, 606608.

(19) Picher, A. J., and Blanco, L. (2007) Human DNA polymerase $\lambda$ is a proficient extender of primer ends paired to 7,8 dihydro 8 oxogua nine. DNA Repair 6, 17491756.

(20) Garcia Diaz, M., Bebenek, K., Kunkel, T. A., and Blanco, L. (2001) Identification of an intrinsic $S^{\prime}$ deoxyribose $S$ phosphate lyase activity in human DNA polymerase $\lambda$. J. Biol. Chem. 276, 3465934663

(21) van Loon, B., and Hübscher, U. (2009) An 8 oxo guanine repair pathway coordinated by MUTYH glycosylase and DNA poly merase $\lambda$. Proc. Natl. Acad. Sci. U.S.A. 106, 1820118206.

(22) Tano, K., Nakamura, J., Asagoshi, K., Arakawa, H., Sonoda, E. Braithwaite, E. K., Prasad, R., Buerstedde, J. M., Takeda, S., Watanabe, M., and Wilson, S. H. (2007) Interplay between DNA polymerases $\beta$ and $\lambda$ in repair of oxidation DNA damage in chicken DT40 cells. DNA Repair 6, 869875 .

(23) Braithwaite, E. K., Kedar, P. S., Stumpo, D. J., Bertocci, B. Freedman, J. H., Samson, L. D., and Wilson, S. H. (2010) DNA Polymerases $\beta$ and $\lambda$ mediate overlapping and independent roles in base excision repair in mouse embryonic fibroblasts. PLoS One 5 , e12229.

(24) Albertella, M. R., Lau, A., and O'Connor, M. J. (2005) The overexpression of specialized DNA polymerases in cancer. DNA Repair 4, 583593.

(25) Martin, S. A., McCabe, N., Mullarkey, M., Cummins, R, Burgess, D. J., Nakabeppu, Y., Oka, S., Kay, E., Lord, C. J., and Ashworth, A. (2010) DNA polymerases as potential therapeutic targets for cancers deficient in the DNA mismatch repair proteins MSH2 or MLH1. Cancer Cell 17, 235248.

(26) Mizushina, Y., Saito, A., Tanaka, A., Nakajima, N., Kuriyama, I., Takemura, M., Takeuchi, T., Sugawara, F., and Yoshida, H. (2005) Structural analysis of catechin derivatives as mammalian DNA poly merase inhibitors. Biochem. Biophys. Res. Commun. 333, 101109.

(27) Summerer, D., Rudinger, N. Z., Detmer, I., and Marx, A. (2005) Enhanced DNA polymerase mismatch extension fidelity by directed combinatorial enzyme design. Angew. Chem., Int. Ed. 44, 47124715.

(28) Gloeckner, C., Kranaster, R, and Marx, A. (2010) Directed evolution of DNA polymerases: construction and screening of DNA polymerase mutant libraries. Curr. Protoc. Chem. Biol. 2, 89109.

(29) Singh, S. P., Parmar, S. S., Raman, K., and Stenberg, V. I. (1981) Chemistry and biological activity of thiazolidinones. Chem. Rev. 81, 175203.

(30) Verma, A., and Saraf, S. K. (2008) 4 Thiazolidinone a biolo gically active scaffold. Eur. J. Med. Chem. 43, 897905.

(31) Tomasic, T., and Masic, L. P. (2009) Rhodanine as a privileged scaffold in drug discovery. Curr. Med. Chem. 16, 15961629. 
(32) Ramadan, K., Shevelev, I., Maga, G., and Hübscher, U. (2004) De novo DNA synthesis by human DNA polymerase $\lambda$, DNA polymerase $\mu$, and terminal deoxyribonucleotidyl transferase. J. Mol. Biol. 339, 395 404.

(33) Maga, G., Ramadan, K., Locatelli, G. A., Shevelev, I., Spadari, S., and Hübscher, U. (2005) DNA elongation by the human DNA polymerase $\lambda$ polymerase and terminal transferase activities are differ entially coordinated by proliferating cell nuclear antigen and replication protein A. J. Biol. Chem. 280, 19711981.

(34) Locatelli, G. A., Di Santo, R, Crespan, E., Costi, R., Roux, A. Hübscher, U., Shevelev, I., Blanca, G., Villani, G., Spadari, S., and Maga, G. (2005) Diketo hexenoic acid derivatives are novel selective non nucleoside inhibitors of mammalian terminal deoxynucleotidyl trans ferases, with potent cytotoxic effect against leukemic cells. Mol. Phar macol. 68,538550 .

(35) Zeiger, E., Anderson, B., Haworth, S., Lawlor, T., Mortelmans, K., and Speck, W. (1987) Salmonella mutagenicity tests: III. Results from the testing of 255 chemicals. Environ. Mutagen. 9 (Suppl. 9), 1109.

(36) Hotta, N., Akanuma, Y., Kawamori, R., Matsuoka, K., Oka, Y., Shichiri, M., Toyota, T., Nakashima, M., Yoshimura, I., Sakamoto, N., and Shigeta, Y. (2006) Long term clinical effects of epalrestat, an aldose reductase inhibitor, on diabetic peripheral neuropathy: the 3 year, multicenter, comparative Aldose Reductase Inhibitor Diabetes Compli cations Trial. Diabetes Care 29, 15381544.

(37) Gu, F., You, C., Liu, J., Chen, A., Yu, Y., Wang, X., Wan, D., Gu, J., Yuan, H., Li, Y., and Lü, H. (2007) Cloning, expression and characterization of human tissue specific DNA polymerase $\lambda 2$. Sci. China Ser. C: Life Sci. 50, 457465. 